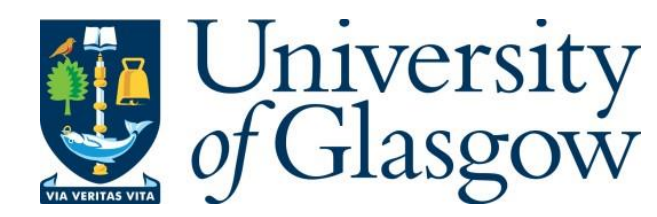

Dassow, J., Li, X., Lee, M.R., Young, M. and Harkness, P. (2020) Ultrasonic drilling for the characterisation of building stones and salt induced decay. Ultrasonics, 101, 106018. (doi: 10.1016/j.ultras.2019.106018)

There may be differences between this version and the published version. You are advised to consult the publisher's version if you wish to cite from it.

http://eprints.gla.ac.uk/196683/

Deposited on: 24 September 2019

Enlighten - Research publications by members of the University of Glasgow

http://eprints.gla.ac.uk 


\title{
Ultrasonic drilling for the characterisation of building stones and salt induced decay
}

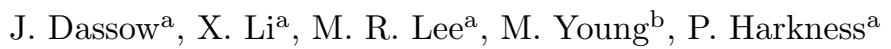 \\ ${ }^{a}$ University of Glasgow, College of Science and Engineering, University Avenue, Glasgow G12 8QQ, Scotland \\ ${ }^{b}$ Historic Environment Scotland, Forthside Way, Stirling FK8 1QZ, Scotland
}

\begin{abstract}
Historic stone buildings can experience severe decay through salt induced weathering. Decay can be easily seen with the eye but can also occur below the surface. Characterising the changes in the material's structural properties induced by weathering is essential for the evaluation of durability of the stone and for the decision on the best conservation strategy to maintain built heritage. Minimally invasive, in situ tools are needed to establish the location and state of decay at the site. Here an ultrasonic drilling tool is introduced with a specially manufactured tip to monitor subsurface properties of sandstones. Different types of sandstones with varying compressive strength are tested and an artificially weathered sample is investigated. The tool tip wear and exerted force on the drilled samples are evaluated and compared to conventional drilling. Ultrasonic drilling shows promising results for the use in conservation science to assess stone properties and decay.
\end{abstract}

Keywords: ultrasonic drilling, building stone decay, salt weathering, sandstone

\section{Introduction}

When building stones are exposed to a changing environment, they suffer from various types of weathering. One of the most damaging weathering processes is induced by salt minerals such as gypsum $\left(\mathrm{CaSO}_{4} \cdot 2 \mathrm{H}_{2} \mathrm{O}\right)$, halite $(\mathrm{NaCl})$, sylvite $(\mathrm{KCl})$, thenardite $\left(\mathrm{Na}_{2} \mathrm{SO}_{4}\right)$, magnesium sulphate salts (such as epsomite, $\mathrm{MgSO}_{4} \cdot 7 \mathrm{H}_{2} \mathrm{O}$, and hexahydrite, $\mathrm{MgSO}_{4} \cdot 6 \mathrm{H}_{2} \mathrm{O}$ ), and other mineral phases of these salts $[1,2]$. The damage can range from a thin but less damaging surface crust (efflorescence) commonly of gypsum to disintegration of rocks caused by the subsurface florescence of salt minerals $[3,4]$. The stress from growth and dissolution of salts can alter the poromechanical properties of rocks leading to changes in porosity and pore size distribution $[5,6,7,8]$. These changes can further enhance other types of weathering such as biological or physical decay. When salt minerals hydrate, further damage can be caused by volume expansion $[1,6]$. Subflorescence may leave no visible damage on the exposed rock's surface but can lead to complete disintegration from the interior. Investigation of the subsurface of the building stone is necessary where their mineralogical and petrophysical properties enhance salt decay and where environmental conditions fluctuate rapidly such as wetting and drying or temperature changes [9].

Investigating buildings stones and their state of decay is important to make an informed decision on best practise for conservation strategies to preserve built heritage and to reduce maintenance costs. No common procedure is established for laboratory or in situ testing of building material

Email address: j.dassow.1@research.gla.ac.uk (J. Dassow)
[10]. Techniques to investigate decay of building stones need to be minimally invasive to preserve the often historic structure and aesthetics of the stone building. The testing methods used need to deliver comparable and repeatable data to characterise the state of decay of the stone at depth. To date several non-destructive to minimally invasive techniques are combined to enable in situ investigation of the surface of the rocks or to the near subsurface to often undefined depths [11]. Drilling into the building stone can provide precise information on the structural changes in the rock at depth $[12,13,14,15]$. Conventional drilling tools that have been developed for this purpose and tested in the last decades include the DRMS or Durabo $[12,14,16]$. The DRMS provides information on subsurface properties through the drilling resistance of the investigated rocks by measuring the force needed to penetrate the rock. A linear correlation between drilling resistance and uniaxial compressive strength (UCS) as well as porosity can be assumed $[17,18]$.

When drilling abrasive rock types such as quartz rich sandstones, an increased wear on the drill tip is unavoidable and requires frequent change of expensive drill bits. Methods to compensate or correct the wear of the drill bits include the drilling of a pilot hole or the frequent drilling of reference materials, which however increases the number of holes needed to be drilled and therefore again the wear of the tool as well as a time-consuming drilling process and correction [19, 20, 21]. When drilling different building stones/materials with varying hardness, given by the compressive strength of the rock, the settings of the tool need to be adjusted for the investigated materials. This process makes it difficult to compare different build- 
ing materials when for example the rotation per minute is doubled or the progression speed into the tool is reduced.

Ultrasonic drilling has been shown to overcome several disadvantages of conventional drilling especially in manufacturing industry: a reduced average force for some materials, easy penetration of hard materials and a reduced wear for some materials [22, 23, 24, 25, 26, 27].

An increase in vibration amplitude can reduce the torque [23]. When assessing the force reduction the ratio of the vibration amplitude and cutting velocity in addition to the contact time of the drill bit and the sample have to be considered [27]. Velocity, contact time and impact angle are given by the set amplitude, frequency and cutting-as well as rotation speed. In rotary ultrasonic machining the cutting force has been investigated in relation to the vibration stability. The latter can be altered by a changing resonant frequency of the tool through its thermo-mechanical load $[28,29]$. The cutting force can decrease when ultrasonic power/amplitude and rotation rate increase, and the progression rate (how fast the machine advances into the sample) decreases [30]. Controlling these variables can improve the material removal rate [29]. For example using sonic drilling can reduce $90 \%$ of the force needed to drill into sandstone, with a given oscillation amplitude of $20-30 \mu \mathrm{m}$ [31]. [32] measured a decrease up to $50 \%$ for a $10 \mu \mathrm{m}$ amplitude in ceramics. [23] investigated marble and granite and with an amplitude of $18 \mu \mathrm{m}$ and a cutting speed of $3 \mathrm{~mm} / \mathrm{min}$. A reduction in torque can be up to $80 \%$ for marble and $40 \%$ for granite. An increased rotation rate decreases the thrust force but a too high weight on bit and soft material can result in an increased thrust force due to debris accumulation $[33,34]$.

In this paper we introduce an ultrasonic drilling tool to monitor subsurface structural changes in building stones. The consumed power is linked to the properties of the drilled material. An artificially weathered building stone is used to investigate locally confined damage by salt induced decay. The design and performance of the tool is described and a newly developed drill bit is introduced. The application is then compared to a conventional drill tool.

\section{Material and Methods}

\subsection{Drilling techniques}

\subsubsection{Ultrasonic Assisted Drilling (UAD)}

Ultrasonic assisted drilling differs from conventional drilling in being characterised by a micro-hammering into the rock. The ultrasonic drill tool includes three main components: a transducer, that transforms electrical energy into a directed motion (here with a frequency around $20 \mathrm{kHz}$ ); an ultrasonic horn that is designed to amplify this oscillation; and the drill bit to reduce wear and remove debris (Figure 1). The ultrasonic transducer used is a Sonic Systems L500 device powered by a P100 control unit. The device is a half-wavelength system with

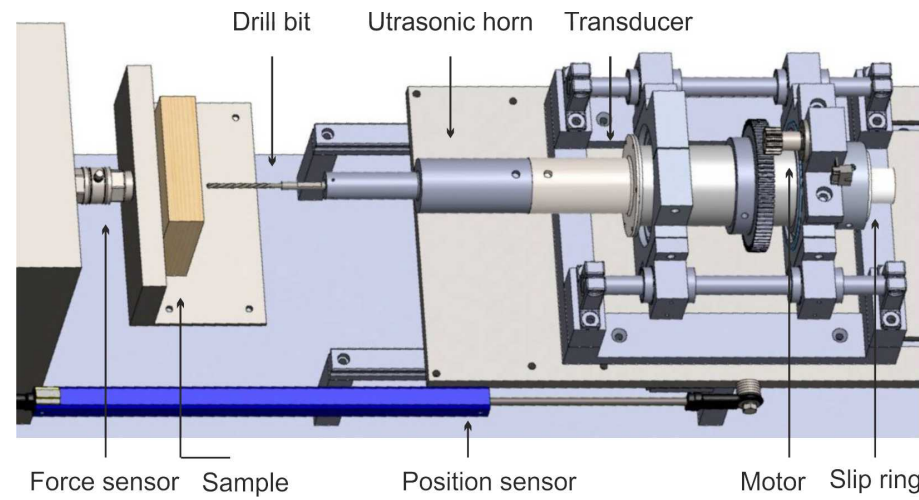

Figure 1: Assembly of the UAD with the drill bit, ultrasonic horn and transducer. For the rotation a motor with two gears attached to the casing of the transducer is added next to the slip ring. The force and position sensor as well as the consumed power are monitored with a sampling rate of $5 \mathrm{kHz}$. A linear actuator (beneath the tool) moves the rig forward at a constant rate.

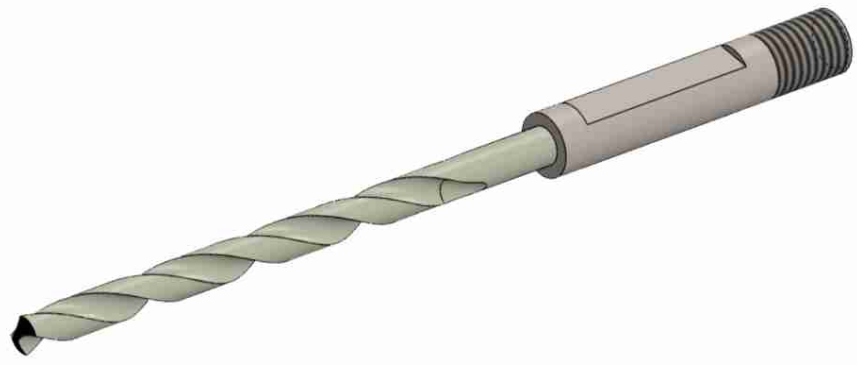

Figure 2: Drawing of the drill bit developed for the UAD with a PCD tip from element6 manufactured by David Richards Engineering (SolidWorks).
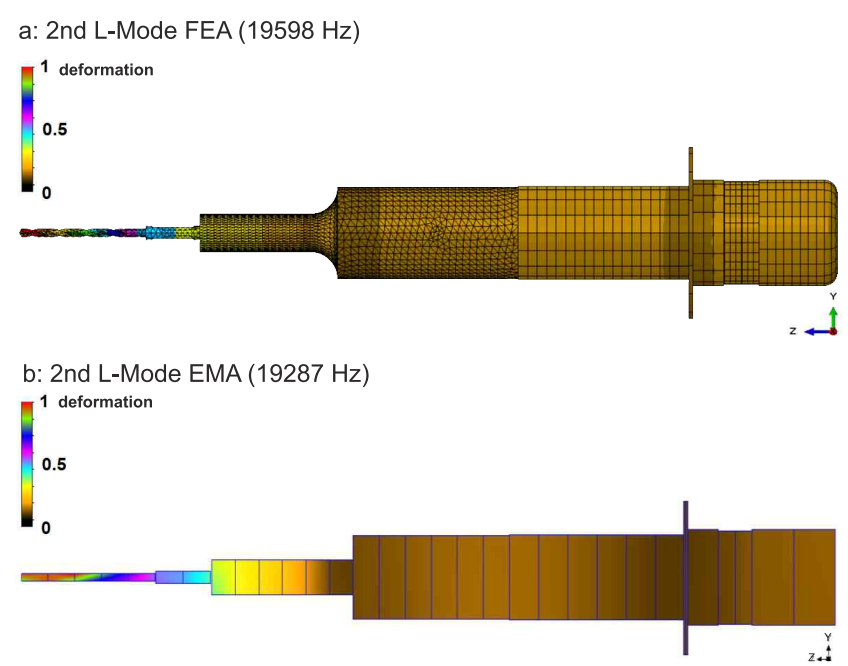

Figure 3: Comparison of the Finite Element Analysis and the Experimental Modal Analysis of the drill bit, ultrasonic horn and transducer. The temperature scale shows the deformation of the tool for the second longitudinal mode modeled at $19598 \mathrm{~Hz}$ and experimentally determined at $19287 \mathrm{~Hz}$ (Abaqus and ME'scopeVES). 
piezoceramics. Displacement can be adjusted from 2 to $12 \mu \mathrm{m}$ peak-to-peak depending on the input power. A half-wavelength step horn is designed to maximise the oscillating amplitude. The increase in amplitude is given by the squared ratio of the two diameters of the horn $\left(\frac{d_{1}}{d_{2}}\right)^{2}$ (Figure 1), which results in a theoretical gain of 4 for the designed horn [22].

A twist drill bit was designed with specifically manufactured polycrystalline diamond tip (PCD) from element six and a threaded shank attachment to connect the ultrasonic horn to the drill bit tip. The drill bit has a diameter of $3 \mathrm{~mm}$ and is made mainly of tungsten carbide (Figure 2). Finite Element Analysis of the parts was undertaken in Abaqus to model the proposed oscillation and later confirmed in the Experimental Modal Analysis with ME'scopeVES (Figure 3).

The ultrasonic transducer and horn are rotated by a cog gear seated at the transducer and driven by a pinion attached to a Maxon DC Geared Motor (B72DB9E3BD8D). A slip ring is used to couple the electrical connections between the P100 (resonance tracking) unit and the piezoceramic rings. The rotation of the drill tool is essential for the removal of debris during drilling. A Kistler force sensor (9321 B) measures compression during drilling to monitor the exerted force on the sample. The progression of the drill tool into the rock is controlled by a DC linear actuator (LT225-1-300P). In addition a position sensor (PS-C15M 200 PS-C15M Linear Potentiometer) measures the progress of the tool. PicoScope records the data with a sampling rate of $5000 \mathrm{~Hz}$. The power consumption is monitored during drilling. A decrease in power consumed indicates a material that is easier to penetrate. To maintain a constant oscillation in different materials with varying hardness the consumed power varies accordingly.

\subsubsection{Conventional Drilling (CD)}

Conventional drilling was undertaken using the Drilling Resistance Measurement System (DRMS) from SINT. The DRMS is operated with two motors to ensure a constant rotation speed from 20 to $1000 \mathrm{rpm}$ and a penetration rate from 1 to $80 \mathrm{~mm} / \mathrm{min}$. These parameters need to be adjusted for the material drilled. A load cell measures the force exerted on the drill tip during penetration with a limit of 100 N. 3 or $5 \mathrm{~mm}$ diameter PCD drill bits are provided by SINT. The tool is portable and can be handheld. For repeatable results the operator needs to keep the tool steady during penetration.

\subsection{Samples and sample preparation}

Four types of sandstones commonly used as building stones in Scotland and a halite sample were drilled [35, 36]. Sample dimensions are $8 \mathrm{~cm} \times 5 \mathrm{~cm} \times 8 \mathrm{~cm}$. The first one is Cullalo, a Carboniferous white quartz arenite containing primarily quartz and less than $10 \%$ of other components. The well sorted sandstone has grain sizes $\sim 200$ microns with quartz overgrowths. Porosity is $\sim 18 \%$ and uniaxial compressive strength (UCS) is $\sim 49 \mathrm{MPa}[37,38]$. Locharbriggs is a Permian red subarkose mainly with quartz and feldspar. Grain size varies with $\sim 200$ microns with a moderate sorting with mainly clay cement present. The porosity is $19 \%$ and UCS starts at $\sim 28 \mathrm{MPa}[37,38]$. Stanton Moor is a Carboniferous blonde subarkose mainly containing quartz, K- and Na-feldspar, and small amounts of muscovite. The sandstone has grain sizes of $\sim 200$ microns, a poor sorting and mainly quartz cement [37]. The porsosity is $14 \%$ and the UCS starts at $\sim 51 \mathrm{MPa}[37,38,39]$. St. Bees is a Triassic red lithic arkose. The grains are well sorted with sizes $\sim 150$ microns. Cement mainly consist of clays and calcite. The porosity is $\sim 20 \%$ and the UCS is between 79 - $100 \mathrm{MPa}[37,39]$. A crystalline halite $(\mathrm{NaCl})$ sample was also used. The UCS of rock salt is $\sim 14 \mathrm{MPa}$ [40].

To induce subflorescence, a Stanton Moor sample was treated with $14 \% \mathrm{Na}_{2} \mathrm{SO}_{4}$-solution and a water repellent to avoid efflorescence. Cyclic wetting and drying with the salt solution was undertaken based on the treatment by [13]: Four sides of the sample were sealed with epoxy to prevent drying from those sides. One of the unsealed sides, where drying should take place, was treated with $5 \%$ sodium methylsiliconate solution. During drying, this water repellent forces the drying front into the inside of the sample. The untreated side of the sample was placed into $14 \% \mathrm{Na}_{2} \mathrm{SO}_{4}$-solution for 3 hours. This was followed by a drying phase of 24 hours in the oven at $45^{\circ} \mathrm{C}$. The cycle of wetting and drying was repeated four times for a controlled damage induction below the rocks' surface.

\subsection{Experiments and settings}

Four different tests were undertaken to investigate rock types, exerted force on the sample, weathering and tool tip wear. Table 1 summarises the different investigations. The first test investigates the performance of the ultrasonic assisted tool for the four different sandstone types, which are common replacement stones in Scotland. These include Locharbriggs, Cullalo, Stanton Moor and St. Bees. During the tests with the UAD the experimental settings are kept constant: The developed drill bit is used with a constant progression rate of $36 \mathrm{~mm} / \mathrm{min}$ and a rotation speed of $200 \mathrm{rpm}$. The sandstones are drilled perpendicular to the bedding to a depth of $15 \mathrm{~mm}$

The second test measures the exerted force on a halite sample during conventional drilling and ultrasonic assisted drilling. The force exerted on the sample by the DRMS and the UAD are compared.

The next test aims to locate subsurface damage caused by artificial weathering in a Stanton Moor sample. The samples are drilled perpendicular to the bedding and the forced drying front of the sample. The depths of the holes drilled is increased to $35 \mathrm{~mm}$.

The last experiment investigates the wear of two different drill bits used during testing. To quantify the wear of the tip, the exerted force on the sample was examined during 
Table 1: Experimental settings for the Drilling Resistance Measurement System (DRMS) and ultrasonic assisted drilling (UAD)

\begin{tabular}{|c|c|c|c|c|}
\hline Experiment & I Stone type & II Force & III Decay & IV Wear \\
\hline $\begin{array}{l}\text { Oscillation frequency (UAD) } \\
{[\mathrm{Hz}]}\end{array}$ & 20000 & 20000 & 20000 & - \\
\hline $\begin{array}{l}\text { Oscillation amplitude (UAD) } \\
{[\mu \mathrm{m}]}\end{array}$ & 2.1 & 2.1 & 2.1 & - \\
\hline $\begin{array}{l}\text { Progression } \quad \text { rate } \quad \text { (UAD) } \\
{[\mathrm{mm} / \mathrm{m}]}\end{array}$ & 36 & 36 & 36 & 36 \\
\hline Rotation speed (UAD) [rpm] & 200 & 200 & 200 & - \\
\hline $\begin{array}{l}\text { Progression rate (DRMS) } \\
{[\mathrm{mm} / \mathrm{m}]}\end{array}$ & - & 10 & 10 & 10 \\
\hline Rotation speed (DRMS) [rpm] & - & 200 & 200 & 400 \\
\hline Drill bit & DB & DB, SINT & $\mathrm{DB}, \mathrm{SINT}$ & $\mathrm{DB}, \mathrm{SINT}$ \\
\hline Rock type & $\begin{array}{l}\text { Locharbriggs, } \\
\text { Cullalo, Stanton } \\
\text { Moor, St. Bees }\end{array}$ & halite & $\begin{array}{l}\text { Stanton Moor, } \\
\text { artificially } \\
\text { weathered }\end{array}$ & Stanton Moor \\
\hline Hole depth $[\mathrm{mm}]$ & 15 & 15 & 35 & 15 \\
\hline Number of holes & 5 per stone & 3 per tool & 3 per tool & $\begin{array}{l}27 \mathrm{SINT}, \\
51 \mathrm{DB}\end{array}$ \\
\hline
\end{tabular}

penetration of a Stanton Moor sample with the DRMS. A worn bit exerts more force to penetrate rocks. During conventional drilling with the DRMS the SINT provided drill bit was used. The developed drill bit was also placed into the DRMS and tested under the same condition. The test was stopped after 50 drilled holes. For the wear investigation the rotation speed of the DRMS needs to be increased to $400 \mathrm{rpm}$ instead of the $200 \mathrm{rpm}$ to enable a penetration of the rock without very quickly reaching the $100 \mathrm{~N}$ force limit of the tool for the SINT drill bit.

Furthermore a previously used, developed drill bit was tested, which previously had drilled more than 30 holes during UAD. The same drill bit had on top drilled more than 20 holes of soft sandstone, also during UAD. This drill bit was then placed into the DRMS to measure the exerted force on the Stanton Moor sample during conventional drilling.

\section{Results}

\subsection{Rock type}

The average consumed power during drilling of five holes to a depth of $1.5 \mathrm{~cm}$ for each stone type is displayed in Figure 4. The power consumption to maintain the oscillation varies depending on the compressive strength or hardness of the rock, with the lowest power consumption for the Locharbriggs sandstone and the highest for the hardest sandstone, St. Bees. It can be observed that the standard deviation during drilling increases with the hardness of the rock (Figure 4). The four different sandstones with varying compressive strength can be differentiated with the UAD tool without having to change the operational settings of the device.

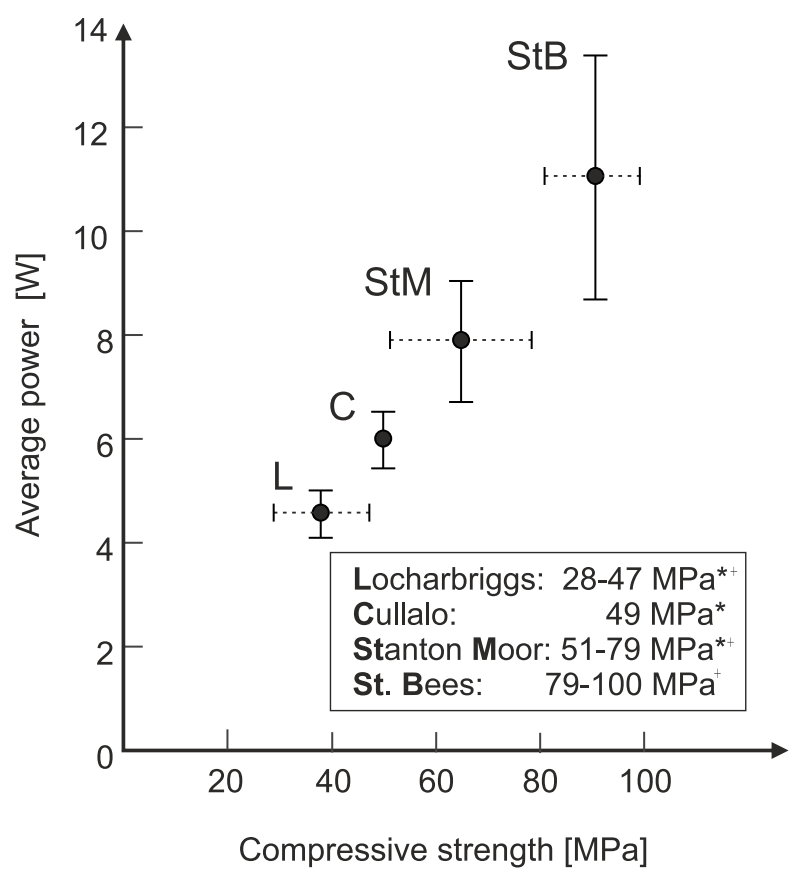

Figure 4: Average consumed power (with standard deviation) for the UAD of five holes drilled with $1.5 \mathrm{~cm}$ depth for different rock types. In the legend the range of the UCS (dashed line) is displayed from t[39] and *[38]. 


\subsection{Exerted force}
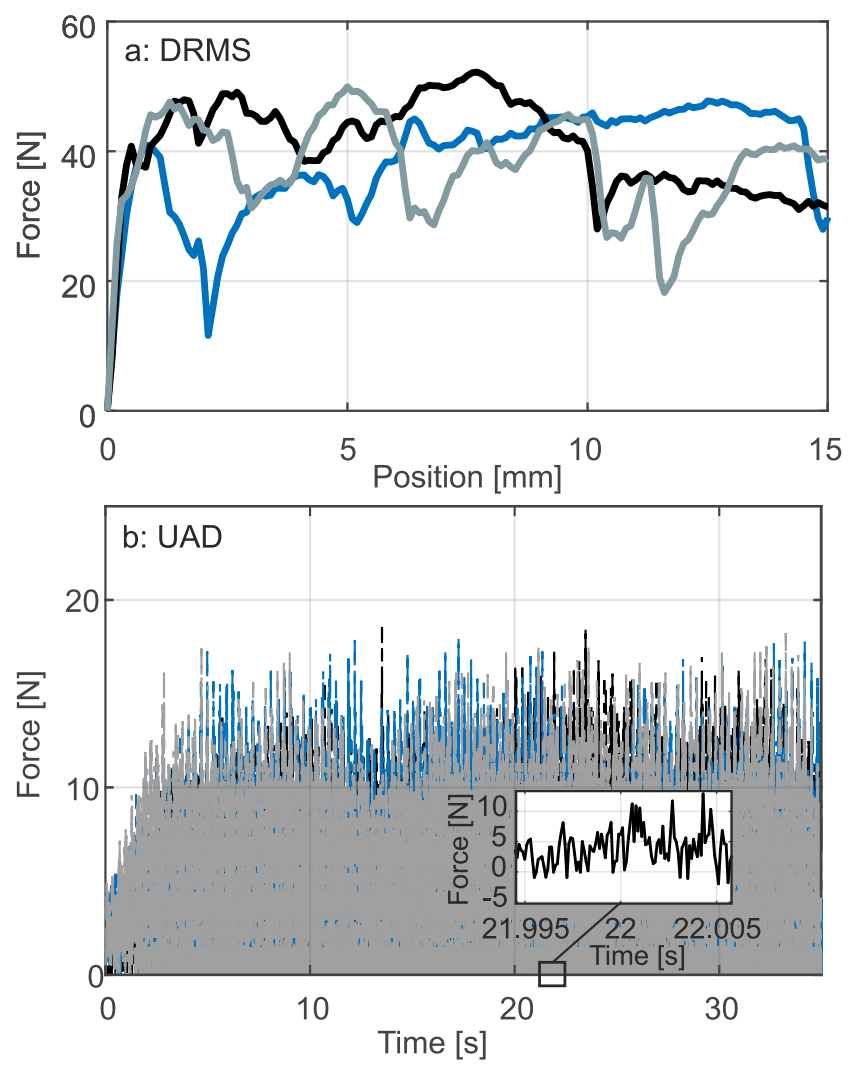

Figure 5: Exerted force on a halite sample for different drilling techniques. a: Force measured with the DRMS for three holes of a depth of $15 \mathrm{~mm}$. b: Force measured during ultrasonic drilling over $35 \mathrm{~s}$ (which relates to a depth of $15 \mathrm{~mm}$ ) and a sampling rate of $5 \mathrm{kHz}$.

Figure 5 shows the results of three holes drilled into a halite sample with the UAD and CD techniques. Figure 5 a shows the exerted force measured with the DRMS for CD for a depth of $15 \mathrm{~mm}$. The force needed to drill a halite sample with the settings described in Table 1 is on average $39.3 \mathrm{~N}$ for the three drilled holes with a standard deviation of $7.6 \mathrm{~N}$. The measured force during the UAD is clearly below $20 \mathrm{~N}$ for the halite sample and on average $4.6 \mathrm{~N}$ with a standard deviation of $2.7 \mathrm{~N}$. Here the exerted force is given per time not drilled depths, because of the more accurate display of the sampling rate of the Kistler force sensor with a sampling rate of $5 \mathrm{kHz}$. The progression rate or more accurately the position sensor provides the depth of the drill bit. $35 \mathrm{~s}$ of drilling a halite sample with the UAD approximates a drilling depths of $15 \mathrm{~mm}$.

\subsection{Artificially weathered sample}

An artificially weathered sample was drilled with the UAD and DRMS. Figure 6 a shows a cross section of the drilled sample. Subflorescence forced a gap of around $5 \mathrm{~mm}$ into the sample. The depths of weathering can be therefore inferred visually from the cross section. Figure $6 \mathrm{~b}$ shows the exerted force on the sample measured
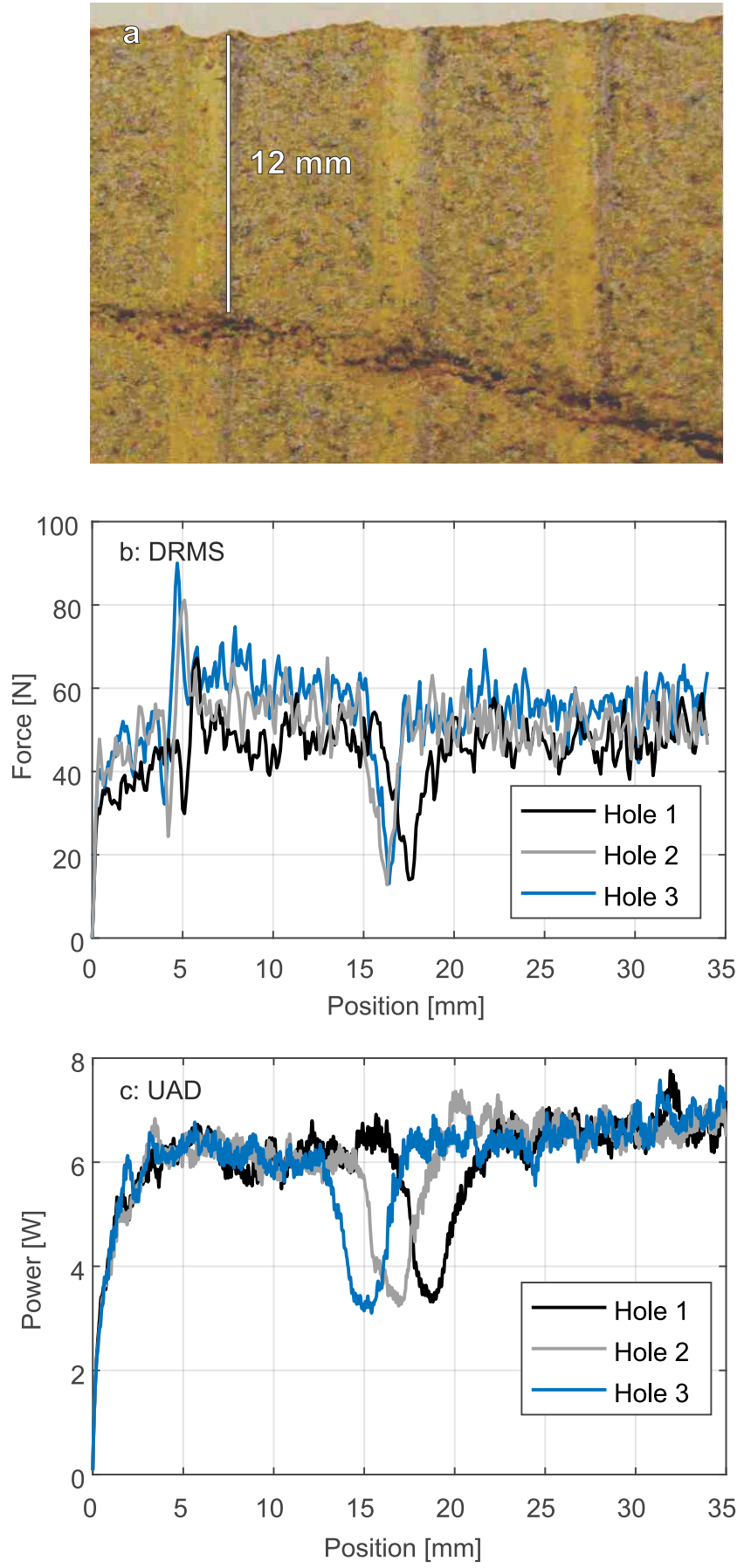

Figure 6: Investigation of an artificially weathered Stanton Moor sample. a: Photograph of a cross-section of the drilled sample. The cyclic drying and wetting with $14 \%-\mathrm{Na}_{2} \mathrm{SO}_{4}$ solution caused a crack to form below the surface. Holes were drilled perpendicular to the surface. b: Exerted force on the sample measured with the DRMS over a depth of $35 \mathrm{~mm}$. c: Consumed power of the UAD during drilling to a depth of $35 \mathrm{~mm}$.

by the DRMS to a depth of $35 \mathrm{~mm}$. A distinct drop in the exerted force identifies the position of the damage in the sample, but also an initial increase around $5 \mathrm{~mm}$ depths can be observed (see Section 4.3). When comparing the 
holes drilled a general increase of exerted force from hole 1 to hole 3 can be seen.

For the UAD (Figure $6 \mathrm{c}$ ) the consumed power is displayed also to a depth of $35 \mathrm{~mm}$. The decrease in power clearly marks the start of the damage in the sample. The power consumed before and after reaching the gap is similar for all holes.

\subsection{Tool wear}

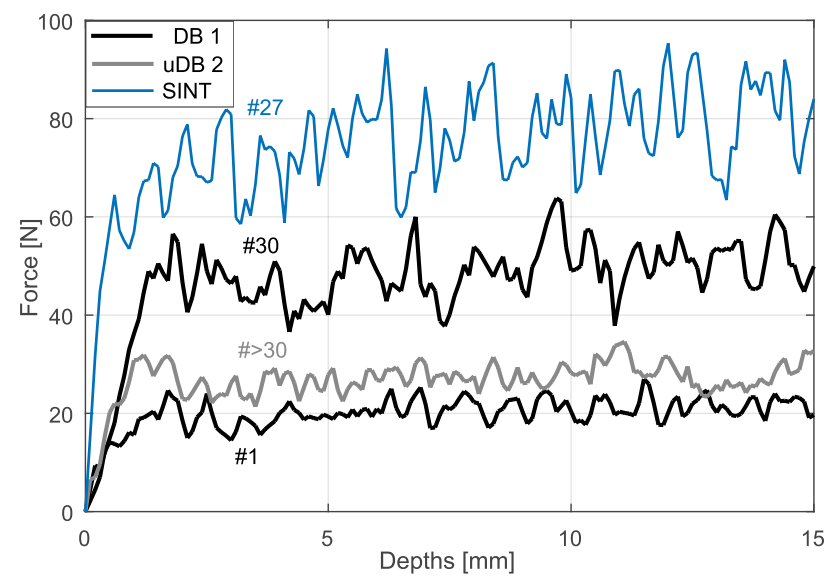

Figure 7: Exerted force on a Stanton Moor sample measured with the DRMS while drilling $15 \mathrm{~mm}$ for different drill bits. In black the performance of a new, developed drill bit during drilling its first $15 \mathrm{~mm}$ (Hole 1). The same drill bit (DB 1) while drilling hole 30 (after drilling a total depth of $45 \mathrm{~cm}$ ). In blue is the performance of the SINT drill bit for hole 27, before it stopped working as the limit of $100 \mathrm{~N}$ was reached. In grey is DB 2, a second developed drill bit that had been used for ultrasonic drilling for more than 30 holes and was then used in the DRMS to measure the force during conventional drilling.

Figure 7 shows the exerted force during conventional drilling of a Stanton Moor sample with different drill bits ( $\mathrm{DB}=$ developed drill bit and $\mathrm{SINT}=$ purchased drill bit $)$. DB 1 shows the force exerted during the drilling of the first $15 \mathrm{~mm}$ and also an example of the force exerted on the sample with the same drill bit drilling hole 30 . In blue the purchased SINT drill bit after drilling a total depths of $37.5 \mathrm{~cm}$ (hole 27). For hole 28/after hole 28 the SINT drill bit could not be used again, because the $100 \mathrm{~N}$ limit of the DRMS was reached. In grey is the exerted force on the sample with a second developed drill bit (uDB 2), that had been used previously for ultrasonic drilling of more than 30 holes. In addition it has also been used for ultrasonic drilling of soft sandstone of more than 15 holes. When placed into the DRMS it shows a similar performance as the new developed drill bit (DB 1).

\section{Discussion}

\subsection{Rock type}

A clear trend can be observed for the sandstones: the increase in power consumption is linked to the increase in hardness/UCS. This is consistent with results from [37] where a wider range of stone types have been tested. UAD allows the drilling of all stone types without changing the given settings.

The hardness of the samples is inferred from their UCS. As compressive strength can differ between layers of the same rock type, an investigation of the UCS should be undertaken for the samples used and further analysis: The mineralogical and physical properties of the rocks are different in addition to the UCS, which also needs to be considered in addition to UCS for the evaluation of the consumed power. The exact relation of power consumption and UCS as well as mineralogical properties needs to be identified by additional tests of varying stone types and precise petrophysical characterisation of the samples. A reference catalogue of building stones could then be created and used to predict stone properties by the recorded power consumption.

\subsection{Average force}

When comparing the average force exerted on a halite sample, the UAD shows on clearly lower average values. Not only the average force but also the maximum force on the sample, that was measured intermittently, is predominantly less than half the force measured during CD. It has to be considered that the sampling rate of the force sensor of the UAD is $5000 \mathrm{~Hz}$ which is only a quarter of the oscillation frequency of the UAD itself. Therefore some information is lost and might exclude higher or lower force values. On the other hand the $5 \mathrm{kHz}$ sampling rate of the force sensor shows that high force events are uncommon. This is of course depended on the settings of both tools. The settings were kept as similar as possible for the two different drilling techniques but also enabling a good signal-to-noise ratio for both tools.

\subsection{Artificially weathered sample}

$\mathrm{Na}_{2} \mathrm{SO}_{4}$ treatment forces a gap in the bulk sample. Both drilling techniques enable a clear identification of the location of this damage. The position of the gap matches the visual observations from the cross sections of the drilled sample with an error of $1.3 \mathrm{~mm}$ for the DRMS and $2 \mathrm{~mm}$ for the UAD. The visual examination identifies clearly visible gaps or larger salt accumulation. It can therefore only be used for an estimation of the location of maximum decay. A microcomputed tomography scan would enable a more precise identification of any changes in the samples. The given error might instead be the error of the visual examination, assuming both analysing techniques are more precise.

The signal-to-noise ratio for the UAD (with a low-pass filter of $10 \mathrm{~Hz}$ ) is better than for the DRMS with an unknown treatment of the recorded force data with the company's software. For the identified gap this trend can be observed even more clearly.

An initial increase in exerted force measured by the DRMS 
can be due to the effects of the water repellent used. The treatment can result in another drying front just below the penetration depths of the water repellent and also increase density in this area. This increase has been observed with both tools during the investigation of other samples and also depends on the position of the hole as well as on the tool wear.

The exerted force measured on the sample during CD increases with every hole drilled. For drilling only a small amount of holes the SINT tool tip already suffers wear whereas the tool tip of the UAD shows a constant power consumption for the three holes drilled.

\subsection{Tool wear}

The force exerted on a Stanton Moor sample with different drill bits of the same diameter, but different tip geometry/suppliers allows a good comparison of the drill bit's performance and wear. It was demonstrated that drilling an abrasive sandstone such as Stanton Moor very quickly blunted the drill bit provided by SINT (see blue graph in Figure 7). After drilling $37.5 \mathrm{~cm}$ (27 holes of a depth of $15 \mathrm{~mm}$ ) of the sandstone this drill bit could not be used with the DRMS again as the force needed to penetrate the stone reached the device's limit of $100 \mathrm{~N}$. The drill bit developed in the study showed a good performance after 30 holes drilled. Furthermore a second developed drill bit of the same type demonstrated a very good performance after being used only for ultrasonic drilling. After UAD of $50 \mathrm{~cm}$ of abrasive sandstone (and around $30 \mathrm{~cm}$ of softer sandstones and limestones) the same drill bit was used in the DRMS to measure the exerted force. In comparison to the other developed drill bit, which was used during $50 \mathrm{~cm}$ of conventional drilling, it was found that ultrasonic drilling of sandstone has clearly reduced the influence of wear on the performance of the drill bit. Therefore the life span of the developed drill bit is increased, especially when used for UAD.

In the future different drill bit shapes/PCD shapes should be investigated for the purpose of ultrasonic rock drilling and with a focus on debris material removal. The pointed shape of the developed drill bit showed a good performance.

Future investigations need to focus on the development of a portable tool and different building materials such as concrete or granite should be tested. So far the tool allows for a better comparison on different building materials as the same settings can be used for soft and hard sandstones. In addition the quality of conservation treatments could be assessed and the lower sensitivity of the tool for density/ porosity variations should be set. This could for example include the penetration depths of desalination treatments or consolidants. Limitations of the tool need to be defined to mark a detection limit for individual materials or material properties.

The application of UAD in conservation science has proven to be advantageous over conventional drilling. The application presented could also be used for non-terrestrial weathering investigation (e.g., on Mars rovers) and subsurface rock properties could be investigated.

\section{Conclusion}

The key conclusions of our investigation of sandstones, halite and artificially weathered samples are as follows:

1. Ultrasonic assisted drilling and the monitoring of power consumption enabled differentiation of building stone type and properties. The same settings can be used for different types of sandstones.

2. Less average force is exerted on the sample with ultrasonic drilling than conventional drilling. The reduction in force was nearly $90 \%$ for halite.

3. Subsurface salt decay can be mapped with UAD. Changes in the structural properties of the rock influence the power that is needed to maintain the oscillation and amplitude of the ultrasonic assisted drilling tool. After treatment of a Stanton Moor sandstone through repeated drying and wetting with $\mathrm{Na}_{2} \mathrm{SO}_{4^{-}}$ solution, the sample developed a crack below the surface that can be detected by a decrease in power consumed by the UAD. The same rock investigated with different devices showed that the UAD had a better (lower) signal-to-noise ratio.

4. The drill bit developed in this study shows a better performance than commercially sourced PCD bits during conventional drilling of sandstone samples. Drill bits that were used for extensive ultrasonic assisted drilling show nearly no influence on the performance of the drill bit in comparison to conventional drilling. The performance was assessed by the force that is exerted on a drilled sample.

UAD demonstrated promising advantages over CD. More tests on different materials are needed as well as the completion of a portable tool.

\section{Conflicts of interest}

We wish to confirm that there are no known conflicts of interest associated with this publication and there has been no significant financial support for this work that could have influenced its outcome.

\section{Acknowledgment}

The author likes to thank Historic Environment Scotland and the University of Glasgow for funding the study and element six for the support with the development of the drill bit. 


\section{References}

[1] M. Steiger, K. Linnow, H. Juling, G. Gülker, A. El Jarad, S. Brüggerhoff, and D. Kirchner. Hydration of $\mathrm{MgSO}_{4} \mathrm{H}_{2} \mathrm{O}$ and generation of stress in porous materials. Crystal Growth 8 Design, 8(1), 2008.

[2] K. Serafeimidis and G. Anagnostou. On the crystallisation pressure of gypsum. Environmental Earth Sciences, 72, 2014.

[3] R. M. Espinosa-Marzal and G. W. Scherer. Impact of inpore salt crystallization on transport properties. Environmental Earth Sciences, 69, 2013.

[4] M. N. Rad, Nima Shokri, Amir Keshmiri, and Philip J. Withers. Effects of grain and pore size on salt precipitation during evaporation from porous media. Transport Porous Media, 110: 281-294, 2015.

[5] G. W. Scherer. Crystallization in pores. Cement and Concrete Research, 29:1347-1358, 1999.

[6] G. W. Scherer. Stress from crystallization of salt. Cement and Concrete Research, 34:1613-1624, 2004.

[7] J. Rüdrich, T. Bartelsen, R. Dohrmann, and S. Siegesmund. Moisture expansion as a deterioration factor for sandstone used in buildings. Environmental Earth Sciences, 2011.

[8] A. Bourges. Holistic Correlation of Physical and Mechanical Properties of Selected Natural Stones for Assessing Durability and Weathering in the Natural Environment. PhD thesis, Ludwigs-Maximilians-Universität München, 2006.

[9] P. A. Warke and B. J. Smith. Effects of direct and indirect heating on the validity of rock weathering simulation studies and durability tests. Geomorphology, 22:347-357, 1998.

[10] B. Lubelli, V. Cnudde, T. Diaz-Goncalves, E. Franzoni, R. P. J. van Hees, I. Ioannou, B. Menendez, C. Nunes, H. Siedel, M. Stefanidou, V. Verges-Belmin, and H. Viles. Towards a more effective and reliable salt crystallization test for porous building materials: state of the art. Materials and Structures, 51(2):55, Apr 2018. ISSN 1871-6873. doi: 10.1617/s11527-018-1180-5.

[11] B. Menendez. Non-Destructive Testing, chapter NonDestructive Techniques Applied to Monumental Stone Conservation, pages 173-214. IntechOpen, 2016.

[12] M. Pamplona, M. Kocher, R. Snethlage, and L. A. Barros. Drilling resistance: overview and outlook. Zeitschrift der Deutschen Gesellschaft für Geowissenschaften, 158:665-676, 2007 .

13] S. Modestou, I. Ioannou, and M. Theodoridou. Salt distribution mapping in natural building and decorative stones. In $A d$ vances in Construction Materials through Science and Engineering Conference (RILEM), 2011.

[14] S. Siegesmund and R. Snethlage. Stone in Architecture, chapter Characterisation of Stone Deterioration on Buildings, pages 347-411. Springer Berlin Heidelberg, 4th edition, 2011.

15] F. Fratini, S. Rescic, and P. Tiano. A new portable system for determining the state of conservation of monumental stones. Materials and Structures, 39:139-147, 2006.

[16] P. Tiano, J. Delgado Rodrigues, E. De Witte, V. Verges-Belmin, S. Massey, R. Snethlage, D. Costa, L. Cadot-Leroux, E. Garrod, and B. Singer. The conservation of monuments: A new method to evalute consolidating treatments. Internationale Zeitschrift fuer Bauinstandsetzen und Baudenkmalpflege, 6(2): 133-150, 2000.

[17] M. Al-Naddaf, F. Wakid, and A. Y. Alhassan. Micro-drilling resistance measurement: A new technique to estimate porosity of a building stone. Mediterranean Archaeology and Archaeometry, 13:225-233, 2013.

[18] M. Theodoridou, F. Dagrain, and I. Ioannou. Correlation of stone properties using standardized methodologies and nonstandardized micro-destructive techniques. In Proceedings of the 12th International Conference on the Deterioration and Conservation of Stone, 2012.

[19] J. D. Rodrigues and D. Costa. A new method for data correction in drill resistance tests for the effect of drill bit wear. International Journal for Restoration, 10(3):1-18, 2004
[20] M. S. Won and C. K. H. Dharan. Chisel edge and pilot hole effects in drilling composite laminates. Journal of Manufacturing Science and Engineering, 124, 2002.

[21] J. M. Mimoso and D. Costa. The DRMS drilling technique with pilot holes. Heritage, Weathering and Conservation, 2006.

[22] J. A. Gallego-Juarez and K. F. Graff, editors. Power Ultrasonics. Woodhead Publishing, 2015.

[23] U. Heisel, R. Eisseler, R. Eber, J. Wallaschek, J. Twiefel, and M. Huang. Ultrasonic-assisted machining of stone. Production Engineering Research and Development, 5:587-594, 2011.

[24] N. K. Maroju, S. Subbu, V. Krishna, A. Vamsi, and A. Venugopal. Vibration assisted conventional and advanced machining: A review. Procedia Engineering, 97:1577 - 1586, 2014.

[25] B. Azarhoushang and J. Akban. Ultrasonically-assisted drilling of Inconel 738-LC. International Journal of Machine Tools and Manufacture, 47:1027-1033, 2007.

[26] R. Tsuboi, Y. Kakinuma, T. Aoyama, H. Ogawa, and S. Hamada. Ultrasonic vibration and cavitation-aided micromachining of hard and brittle materials. Procedia CIRP 1, pages 342-346, 2012.

[27] D.E. Brehl and T.A. Dow. Review of vibration-assisted machining. Pre, 32:153-172, 2007.

[28] J. Wang, P. Feng, J. Zhang, W. Cai, and H. Shen. Investigations on the critical feed rate guaranteeing the effectiveness of rotary ultrasonic machining. 74:81-88, 2017.

29] J. Wang, P. Feng, J. Zhang, and P. Guo. Experimental study on vibration stability in rotary ultrasonic machining of ceramic matrix composites: Cutting force variation at hole entrance. 44: 14386-14392, 2018

[30] W. L. Cong, Z. J. Pei, X. Sun, and C. L. Zhang. Rotary ultrasonic machining of cfrp: A mechanistic predictive model for cutting force. 54:663-675, 2014.

[31] N. Vedvik. Assessment of ultrasonic assisted drilling. Master's thesis, Norwegian University of Science and Technology, 2015.

32] K. Ishikawa, H. Suwabe, T. Nishide, and M. Uneda. A study on combined vibration drilling by ultrasonic and low-frequency vibrations for hard and brittle materials. Precision Engineering, 22:196-205, 1998.

[33] K. Zacny, Y. Bar-Cohen, M. Brennan, G. Briggs, G. Cooper, K. Davis, B. Dolgin, D. Glaser, B. Glass, S. Gorevan, J. Guerrero, C. McKay, G. Paulsen, S. Stanley, and C. Stoker. Drilling systems for extraterrestrial subsurface exploration. Astrobiology, 8(3):665-706, 2008.

[34] V. Baghlani, P. Mehbudia, J. Akbarib, and M. Sohrabi. Ultrasonic assisted deep drilling of Inconel 738LC superalloy. In The Seventeenth CIRP Conference on Electro Physical and Chemical Machining, 2013.

[35] Stancliffstones, 2012

URL http://www. stancliffe.com/UK-Stone-Types-And-Colours/.

[36] I. T. Bunyan, J. A. Fairhurst, A. Mackie, and A. A. McMillan. Building Stones of Edinburgh. Edinburgh Geological Society, 1987.

[37] J. M. I. Dassow. Sensing and understanding the resilience of sandstone. PhD thesis, University of Glasgow, School of Geographical and Earth Sciences, 2018.

[38] C. J. Graham. A petrographic investigation into the durability of common replacement sandstones to the crystallisation of deicing salts. PhD thesis, University of Glasgow, 2016.

[39] BRE. Stonelist, 1997 and $2000 . \quad$ URL http://projects.bre.co.uk/ConDiv/stonelist/stonelist.html.

[40] W. Liang, C. Zhang, H. Gao, X. Yang, S. Xu, and Y. Zhao. Experiments on mechanical properties of salt rocks under cyclic loading. Journal of Rock Mechanics and Geotechnical Engineering, 4:54-61, 2012 . 